\title{
SEguRANÇA E “GUERRA AO TERROR”: UM BALANÇO DA LITERATURA CONTEMPORÂNEA SOBRE A AMÉRICA LATINA APÓS 11 DE SETEMBRO ${ }^{l}$
}

\author{
Marcelo da Silveira Campos ${ }^{2}$ e Andrei Koerner ${ }^{3}$
}

\begin{abstract}
Resumo
0 objetivo deste artigo é revisar e sistematizar parte da bibliografia acadêmica anglosaxã sobre segurança pública e como esta literatura pensa o papel dos EUA na América Latina, no cenário pós 11 de setembro. A conversão da "guerra ao terror" em eixo programático e estruturante das relações bilaterais estabelecidas pelos EUA com os outros países trouxeram modificações no plano da formulação e implementação das políticas de segurança em diversos países do globo. Essas modificações influenciaram a formulação e o modelo das políticas públicas de segurança - sejam as políticas internas adotadas para a sociedade norte-americana, sejam as políticas de segurança dos países que se relacionam (e dos que não se relacionam) com o governo estadunidense. Esta revisão, portanto, analisa os textos produzidos entre os anos de 2001-2010 sobre a temática da assim chamada "guerra ao terror" e América Latina.
\end{abstract}

Palavras-chaves: Políticas de segurança. "Guerra ao terror". América Latina. EUA.

\footnotetext{
${ }^{1}$ Este artigo faz parte de pesquisas do Instituto Nacional de Estudos sobre os Estado Unidos (INCTINEU), realizadas pelo Grupo de Pesquisas sobre Direitos Humanos sobre "As implicações jurídicas da estratégia dos Estados Unidos de combate ao terrorismo".

${ }^{2}$ Doutorando em Sociologia na Universidade de São Paulo e bolsista FAPESP, Brasil. marcelocampos@usp.br

${ }^{3}$ Professor do Departamento de Ciência Política da Universidade Estadual de Campinas, Brasil. andreik@uol.com.br
} 


\title{
SECURITY AND THE 'WAR ON TERROR': A REVIEW OF CONTEMPORARY Literature on Latin America after SEPTEMber 11
}

\begin{abstract}
The objective of this article is to revise and systemize part of the Anglo-Saxon academic bibliography on public security and how this literature views the role of the U.S.A. in Latin America, in the post-September 11 scenery. The conversion of the "war on terror" into programmatic and structuring pivot of bilateral relations established by the U.S.A. with other countries brought modifications in the formulation and implementation plan of security policies in several countries of the globe. These modifications influenced the formulation and model of public security policies - whether they are adopted internal policies for the North-American society, or security policies of the countries that relate (and those who don't relate) with the United States government. This revision, therefore, analyzes the texts produced between the years of 2001-2010 on the theme of thus the so-called "war on terror" and Latin America.
\end{abstract}

Keywords: Security politics, "War on terror". Latin America. U.S.A.

\section{INTRODUÇÃO}

0 s atentados de 11 de setembro de 2001 ocorridos nos EUA proporcionaram um novo rearranjo na política de segurança internacional. A conversão da "guerra ao terror" em eixo programático e estruturante das relações bilaterais dos EUA para com os outros países trouxeram modificações no plano da formulação e implementação das políticas de segurança em diversos países. Essas modificações influenciaram a formulação (e o estilo) das políticas públicas de segurança - sejam as políticas internas adotadas para a sociedade norteamericana, sejam as políticas de segurança dos países que se relacionam (ou não) com o governo estadunidense.

Nesse contexto, torna-se interessante revisar parte da produção bibliográfica recente sobre segurança pública e América Latina. Como a literatura anglo-saxã sobre segurança pública passou a pensar o papel dos EUA na América Latina no cenário pós 11 de setembro? A literatura vê alguma mudança na postura americana? Se sim, quais são essas mudanças? 0 objetivo do trabalho é mapear e sistematizar esta bibliografia acadêmica produzida após os atentados de 11/09, considerando essas questões. Esta revisão analisou os textos produzidos entre os anos de 2001-2010 sobre a temática da "guerra ao terror" e "América Latina". Os textos foram selecionados a partir de uma busca realizada em duas bases de referências bibliográficas: JSTOR e SAGE. A busca foi inicialmente realizada com 
os termos chaves: war on terror e Latin America. No segundo momento, esses termos foram articulados com outras duas palavras: criminal justice e public safety. De antemão, podemos citar como fonte importante de pesquisa sobre a temática os periódicos: Journal of Latin American Studies; Law \& Social Inquiry; Third World Quarterly, Journal of Peace Research, Latin American Perspectives, dentre outros.

0 levantamento bibliográfico parcial mostra a existência de uma literatura que entrecruza trabalhos em torno de um eixo temático principal: os trabalhos sobre segurança pública e justiça criminal que analisam as leis, práticas, instituições estatais e reformas penais promovidas nos países latinoamericanos sob influência direta ou indireta da política estadunidense no período pós 11 de setembro. Em determinados momentos estes trabalhos abordam as alterações nas relações bilaterais dos EUA com países da América Latina em termos de política externa americana, incluindo-a como região estratégica para refúgio, financiamento e presença ativa de grupos terroristas. Embora alguns textos aqui tratem desta questão, este não é o tema principal deste levantamento.

0 texto revisita e sistematiza esta específica produção acadêmica anglosaxã produzida em torno da temática das alterações em leis, normas, arranjos institucionais de segurança pública na América Latina sob os efeitos da "guerra ao terror". 0 recorte temporal da produção acadêmica coincide majoritariamente com 0 período da presidência de George W. Bush, período em que a "war on terror" foi implementada. Assim, este breve balanço segue organizado de modo a oferecer ao leitor uma visão inicial geral dos debates que apareceram no período pós 11/09 sobre as políticas de segurança na região latino-americana. Para ordenar a apresentação dos estudos, o texto é divido em duas grandes seções: i) as pesquisas que abordam a emulação da influência americana nas políticas, leis e normas vigentes na América Latina, influência esta que teria sido intensificada após a "guerra ao terror"; ii) pesquisas que, em menor número, investigam a hipótese inversa que estaria havendo uma "difusão da periferia". Neste último grupo, as mudanças não necessariamente emulam do que a bibliografia denomina de países "centrais" para os países "periféricos", mas investigam-se os contextos institucionais e históricos de cada país. Denominados o primeiro enfoque como "hegemônico" e o segundo como 'periférico'.

\section{O ENFOQUE HEGEMÔNICO}

Um primeiro (e principal) eixo de trabalhos sobre as políticas de segurança pública implementadas pelos países latino-americanos é dado a 
partir do consecutivo argumento: há uma emulação de modelos que foram e são importados pelos países latino-americanos do hemisfério norte, sobretudo a partir dos EUA. Grosso modo, este viés interpretativo analisa como leis, normas e políticas criminais são difundidas do "centro" para a "periferia" (MATTEI, 2003). 0 enfoque tem por preocupação central e comum pensar como os países "centrais" impõem normas, leis e políticas sobre outros estados por meio do uso ou da ameaça da força como incentivos para que estes países satisfaçam interesses materiais e políticos. Tais análises também sugerem que esta difusão é influenciada decisivamente por pressões do capitalismo internacional e expansão do neoliberalismo (LANGER, 2007).

Esses textos partem do pressuposto de que a América Latina é um foco de recepção e experimentação destas políticas por meio da hegemonia americana. Este processo, não teria ocorrido somente após o 11/09, mas após a "guerra ao terror" houve uma intensificação da política, já em vigor desde a Guerra Fria. Também destacam que atualmente a influência e hegemonia de estratégias de contra-insurgência sobre as políticas de segurança (como pacotes econômicos) são utilizados como moeda de troca por pacotes de segurança após 11/09.

Nesta linha, Godoy (2005) afirma que a predominância da lógica econômica neoliberal sobre os países da América Latina contribui para estabilizar um estilo de governança que prioriza o policiamento repressivo e o reforço de barreiras socioeconômicas em detrimento da criação de mecanismos de minimização de desigualdades. Neste estilo de governança 0 aparato estatal serviria a uma minoria economicamente privilegiada, em detrimento de crescentes extratos pauperizados da população. A autora observa que em tais sociedades o sistema e as instituições de justiça criminal tendem a se tornarem mais repressivas, tendo como efeito inevitável, o fortalecimento de fronteiras raciais, religiosas e de classe (MANN, 2002).

Outro argumento bastante presente nestes textos versa sobre o processo de redemocratização da América Latina. Godoy (2005, p. 516) cita que nos últimos 20 anos a América Latina passou por uma onda de reformas políticas e econômicas fortemente influenciadas por modelos de desenvolvimento e de justiça criminal europeu e estadunidense. Essa influência pode ser identificada a partir da crescente adesão aos modelos de policiamento, treinamentos e tecnologias de segurança importadas dos EUA. Um dos exemplos citados por Godoy (e pela maioria dos autores deste enfoque) foi o pacote de medidas de prevenção e repressão à criminalidade conhecido como "tolerância zero". Inicialmente implementado em Nova Iorque, o pacote foi posteriormente adotado em diversos países latino-americanos, sob visita de Giuliani e Bratton a Cidade do México, 
Caracas e outras cidades. A autora ainda cita que a promoção da "guerra às drogas" e ao "terrorismo" pelos EUA vem pressionando líderes políticos da região a adotar medidas de segurança e empreender reformas no sistema judiciário.

Apresentando a progressiva transposição do modelo de segurança estadunidense para países da América Latina, Godoy contempla na análise as possíveis implicações do contrafluxo dessa tendência sobre a democracia estadunidense. Ou seja, a autora identifica uma "convergência de pólos" que identifica semelhanças na orientação e estruturação das políticas de segurança nos EUA com os modelos implementados na América Latina. 0 que parte da literatura denomina de Mano Dura ${ }^{4}$ (GODOY, 2005; HUME, 2007; UNGAR, 2008).

Tal termo traduz uma abordagem policial e política de segurança do tipo "mão de ferro", imediatista e utilizada por diferentes presidentes e governadores latino-americanos. Embora o texto não apresente dados específicos sobre as reformas e políticas nos países da região, Godoy (2005) observa que existem convergências que permitem compreender algumas das características estruturais dessas políticas que permeariam tanto os países "desenvolvidos" quanto países "em desenvolvimento" na atualidade. Isto porque na América Latina a "guerra ao terror" foi precedida pela "guerra contra o crime" e o mesmo aparato repressivo é utilizado internamente nos EUA e na América Latina, segundo o autor. Este aparato acompanha a adoção de medidas promovidas pela guerra ao crime e ao terrorismo em diversos países latino-americanos. A "guerra ao terror" para Godoy promoveu uma intensificação da perspectiva de segurança dura e reativa, que pauta a agenda das políticas de segurança na região.

0 processo de transformação pelo qual os sistemas de punição e controle do crime passam, podem ser identificado no sistema de justiça criminal estadunidense. Segundo Godoy, desde os eventos de 11/09, os EUA aprovam medidas mais severas como: 0 aumento de tempo de reclusão de réus primários; retirada de oportunidades de instrução ou acesso à educação dentro dos presídios; negação de crédito estudantil a pessoas sentenciadas por crimes relacionados ao porte ou uso de drogas que já tenham cumprido sua pena. Outra consequência social das práticas de punição contemporânea americana que "convergem os pólos" é o modo pelo qual as medidas de prevenção e combate à criminalidade e violência estão sendo estruturadas, fazendo com que parte da população - que se relaciona com a justiça criminal - passe a integrar um grupo de "não-cidadãos", sujeitos às medidas mais duras.

${ }^{4}$ Mano dura é uma versão temperada da "tolerância zero". 
Em Mano Dura: El Salvador Responds to Gangs, Hume (2007) avalia 0 contexto político e as estratégias de combate à criminalidade em El Salvador. Com ênfase na estratégia anti-gangues, implementadas no país desde 2003, ele observa a resposta governamental aos altos índices de criminalidade e à forma pela qual essa resposta contribui para agravar o problema no país. A autora cita que não existem muitas informações sobre grupos de jovens com participação no mundo do crime, embora diferentes pesquisas estimem que possam existir entre $10.000 \mathrm{e}$ 39.000 membros de jovens em gangues ativas em El Salvador. Esses grupos seriam compostos, em sua grande maioria, por jovens do sexo masculino oriundos de bairros populares, sendo a Mara Salvatrucha (MS13) e Mara 18 (MS18) as duas maiores gangues do país.

Segundo Hume desde 11/09, os EUA teriam dominado a agenda de política externa mundial e para a América Latina. A definição real de terror é confusa, especialmente vista da perspectiva americana para a América Latina, pois o Pentágono emprega um conceito amplo do que constitui as ameaças à segurança no hemisfério ocidental descrevendo-as como "[...] o crime organizado, tráfico de drogas e as gangues como uma 'combinação de anti-social' que desestabiliza a sociedade e, portanto, representa uma séria ameaça à segurança." (WOLA, 2005 apud HUME, 2007, p. 753).

A promoção dessa política hegemônica provou ser particularmente frutífera como uma estratégia eleitoral para os operadores de El Salvador do partido ARENA5, que utilizou a política Mano Dura para mobilizar o apoio na eleição presidencial de 2004: 88\% da população teria expressado apoio à política de segurança e combate às "gangues juvenis" em uma pesquisa de opinião feita logo após o lançamento da política, em julho de 2003 (ARTIGA GONZALEZ, 2004 apud HUME, 2007, p. 745). 0 sucesso desta abordagem seria baseada em uma retórica emotiva, dependente da construção da imagem de gangues juvenis como um inimigo comum dos "bons cidadãos". 0 ex-presidente Tony Saca, ao tomar posse em 2004, decretou como uma das primeiras ações a atualização do existente Mano Dura em Super Mano Dura. Nesse contexto, milhares de jovens foram detidos no âmbito destas medidas, apesar das alegações de inconstitucionalidade e acusações crescentes de violações dos direitos humanos (FESPAD, 2004 apud HUME, 2007, p. 745). Em todo o país, grupos militares especializados em "antigangues" (Grupos Territoriales Antipandilleros) foram implantados; e tratados de extradição foram assinados junto aos países vizinhos. 0 envolvimento dos EUA

${ }^{5}$ AArena (Aliança Republicana Nacionalista) é um tradicional partido de direita que governou El Salvador de 1989 a 2009. 
na promoção desta agenda têm sido significativo para Hume, pois em 2004, o FBI criou uma força-tarefa especial para combater a atividade de gangues na região, utilizando El Salvador como o seu centro de operações.

A concentração das atenções das políticas de segurança sobre os jovens pobres das periferias consolidou um binarismo antagônico ou "consenso autoritário" que dividiu a sociedade de El Salvador entre "bons cidadãos" de um lado, e a representação de um "inimigo" do outro. Estes últimos - os jovens pobres - são assumidos como ameaça e justificativa para que o estado utilize medidas repressivas indiscriminadamente sobre extratos marginalizados da população. A autora conclui que a orientação "tolerância zero" na política Mano Dura reflete uma profunda crise no processo de consolidação democrática no país, evidenciando o papel histórico da repressão como ferramenta de governança. As "gangues de jovens", eleitas pela administração do país para suplantar a "ameaça comunista", reforçam o clima generalizado de "pânico", a fim de obter o respaldo público para a utilização de medidas repressivas contra a juventude. Tais políticas são ideologicamente fundamentadas e servem para desviar a atenção de outros assuntos de governo (weak governance) fundamentando localmente (sob influência direta americana) as políticas autoritárias e excludentes.

A Colômbia também aparece em artigos que tratam da influência direta ou indireta exercida pelos EUA em território colombiano. Avilés (2006) analisa os grupos paramilitares colombianos e o papel desempenhado por estes durante o período das reformas democráticas no país. Para 0 autor, a análise das relações entre civis e militares durante esse período evidencia o papel das elites locais, das forças armadas e o contexto político econômico internacional no enquadramento das políticas de segurança pública e "consolidação" da democracia na Colômbia. A hipótese de Avilés é que as elites locais lançaram mão de diversos mecanismos estatais como formas de implementação de reformas econômicas neoliberais consolidando um regime denominado de Low-Intensity Democracy, definida pelo autor como: "[...] um regime democrático promovido internacionalmente como um complemento necessário para a disseminação do livre mercado." (AVILÉS, p. 380, 2006, tradução nossa).

0 autor defende que a realização dessas reformas evidencia a adoção de uma nova orientação modernizadora e neoliberal, por parte de certas elites políticas da região, com o intuito de integrar o país à economia global marcando a emergência do que Avilés (2006, p. 2) denomina como "elite colombiana transnacional". Entre 1990 e 2002, segundo o autor, a Colômbia vivenciou simultaneamente reformas democráticas e a abertura econômica associada ao 
crescimento da violência, da repressão política e paramilitar. Para reafirmar seu argumento, Avilés empreende uma análise histórica das relações entre grupos paramilitares e o governo colombiano abarcando a administração Gavíria (19901994), Samper (1994-1998), Pastrana (1998-2002) até o início do mandato de Uribe em 2002. Desse modo, o autor identifica que a manutenção e intensificação das estratégias de combate ao narcotráfico, em detrimento da paralisação dos grupos paramilitares, marcam todas as administrações analisadas.

Esta orientação colombiana encontrou amplo respaldo dos EUA, que a despeito de sua estratégia discursiva em "prol" dos valores e instituições democráticas, ofereceu auxílio militar a unidades e oficiais colombianos sob suspeita de violação aos direitos humanoseenvolvimento com gruposparamilitares. No fim do artigo, Avilés (2006) destaca os ataques de 11/09 e tira algumas consequências institucionais para o contexto atual da Colômbia. Embora não cite exemplos específicos, o autor alerta que a promoção americana da "guerra ao terror" culminou no fortalecimento dos grupos paramilitares, pois muitos aliados da "causa" contra o terrorismo - como a Colômbia - justificam a conivência e a necessidade de grupos paramilitares ou de autodefesa como estratégia auxiliar de segurança. Para o autor, esse posicionamento das autoridades civis colombianas é sustentado ao longo das últimas duas décadas mantendo aberta a ameaça para que grupos paramilitares ganhem mais espaço e projeção dentro da estrutura de repressão estatal colombiana.

Aprofundando a análise sobre as continuidades e descontinuidades entre as políticas de segurança norte-americana e a Colômbia, Zuluaga e Stoller (2007) examinam as políticas de segurança adotadas pelos EUA desde o final da Segunda Guerra Mundial ( $2^{a}$ G.M) até os ataques de 11/09. 0 objetivo central do texto é investigar o impacto que tais políticas exercem sobre a "consolidação da democracia" na Colômbia, bem como o papel desempenhado por esse país na expansão dessas políticas e da hegemonia estadunidense sobre a América Latina.

Os autores localizam o início desse processo ao fim da $2^{\text {a }}$ G.M., momento em que os EUA e a URSS disputavam o estabelecimento de uma hegemonia econômica e política global. Os EUA passaram a orientar tanto a agenda da política externa quanto a de segurança. 0 posicionamento do governo estadunidense resultou em alianças com líderes de diversos países em regimes ditatoriais e na intervenção direta sobre a vida política na América Latina. Aqui, a política de segurança americana desempenhou um papel chave nas estratégias de controle dos países latino-americanos resumidas em três grandes fases: i) "contra a insurgência", o objetivo era "conter" o avanço do comunismo entre 1947 e 1990; ii) "a guerra às 
drogas" que visou "reprimir" o tráfico de drogas entre 1990 e 2001; iii) "a guerra ao terror" desde 2001.

Essa doutrina privilegia a segurança de estado, em detrimento da proteção das garantias e direitos civis, e é fortemente calcada na repressão de um "inimigo interno" (ora representado pelo comunismo, tráfico de drogas ou redes terroristas). Ela só veio a ser denunciada no final da década de 1970 com a emergência de movimentos em prol dos direitos humanos. Segundo a perspectiva do autor, a influência da doutrina de segurança estadunidense sobre a América Latina implicou na legitimação da promoção da segurança nacional por meio de uma crescente militarização da resposta governamental aos conflitos sociais da região.

Zuluaga e Stoller (2007) argumentam que a queda do socialismo, no final da década de 1980, teria acompanhado a reorientação da política externa e de segurança estadunidense, que passou a promover o combate ao tráfico de drogas, acompanhado da defesa da democracia e dos direitos humanos. Entretanto, o autor argumenta que o modo pelo qual tais políticas estão sendo estruturadas mantém a ambiguidade no posicionamento político dos EUA. Por um lado, justifica suas ações intervencionistas proclamando a defesa dos direitos humanos e da democracia, por outro lado, mantém a proteção de tais princípios subordinados a um conjunto de interesses políticos e econômicos estratégicos do país. Essa ambiguidade das políticas de segurança é intensificada após os ataques de 11/09, quando a promoção da "guerra ao terror" viria a se combinar com a "guerra às drogas".

Sobre as relações entre os EUA e Colômbia (ZULUAGA; STOLLER, 2007, p. 117), destaca-se que historicamente a Colômbia se caracterizou como um forte aliado político dos EUA e serviu de "laboratório" para a aplicação de estratégias de combate à ameaça comunista e à guerrilha armada na América Latina, promovida pelos EUA, que combinaram estratégias de combate ao tráfico de drogas entre as décadas de 1970 a 1990. No final da década de 1990, o crescimento dos conflitos internos e o tráfico de drogas foram declarados pelos EUA como uma ameaça à segurança regional, o que culminou no envio de tropas militares à Colômbia. Nesse contexto, os ataques de 11/09 e a intensificação do conflito entre o governo e as Forças Armadas Revolucionárias da Colômbia (FARC), em 2002, contribuíram ainda mais para a incorporação das políticas e estratégias de combate anteriores enquanto parte das políticas de segurança de "guerra ao terror". Como reflexo interno desta aliança, o governo Uribe declara em 2003 na Colômbia a "Defesa e Estratégia de Segurança Democrática", na qual "o terrorismo é um meio de 
minar a estabilidade do estado e a maior ameaça à democracia na Colômbia e no mundo" (ZULUAGA; STOLLER, 2007, p. 117).

0 plano de Uribe definiu os seus principais objetivos estratégicos: i) consolidação do controle estatal sobre todo território nacional; ii) proteção da população; iii) eliminação do tráfico de drogas; iv) manutenção de uma suficiente "capacidade dissuasiva" contra ameaças potenciais. Segundo o autor, Uribe justificou esta orientação dura de sua política de segurança pública apresentando uma significativa diminuição nos índices de violência letais no país, mas obscureceu o posicionamento contraditório de sua gestão conivente com as violações dos direitos humanos. Como exemplos, os autores citam a restrição militar à distribuição de alimentos e remédios em áreas "sob suspeita de domínio dos movimentos guerrilheiros", monitoração da comunicação, constantes ameaças aos jornalistas, prisões de cidadãos sem apresentação de acusações formais ou provas, etc. Portanto, Zuluaga e Stoller (2007) localizam na Colômbia uma perspectiva de segurança pós 11/09 que sobrepõe a defesa e proteção dos direitos humanos, culminando na militarização de diversos aspectos da vida pública nesse país.

Em outra perspectiva, Karstedt e LaFree (2006) apresentam um panorama sobre estudos que relacionam crime, democracia e justiça na contemporaneidade e suas "implicações para a promoção e estabilização da democracia” em diferentes contextos políticos e econômicos. Os autores argumentam que a proteção às liberdades civis e o respeito aos direitos humanos "seriam parte integral do processo de institucionalização democrática em qualquer nação", fazendo com que as relações entre democracia, justiça criminal e o próprio crime sejam relevantes objetos de estudo. Os autores citam a escassez de pesquisas que exploram as relações entre crime e democracia, bem como a carência de estudos comparativos (KARSTEDT; LAFREE, 2006, p. 7) em duas frentes: i) diferentes possibilidades de entrelaçamento e interdependência desses três fatores em um mesmo país; ii) análises comparativas mais amplas, abarcando diferentes regiões ou países.

Para Karstedt e LaFree (2006), embora a consolidação do estado de direito na América Latina seja um dos passos fundamentais para a promoção do regime institucional democrático, grande parte dos processos de transição democrática empreendidos na segunda metade do século XX, sobretudo, América Latina e Leste europeu deixaram de lado as reformas do sistema de justiça criminal. Segundo os autores, esse descompasso entre os processos de consolidação da justiça criminal e de outras instituições políticas em países que estão passando por transições democráticas têm permitido a apropriação da justiça criminal a favor de certos 
grupos políticos autoritários, culminando no que Caldeira e Holston (1999) denominaram de "democracias disjuntivas". Tais arranjos institucionais teriam se popularizado entre países da América Latina (e também do Leste Europeu). Um dos exemplos citados pelos autores é o Brasil, que apresentaria altas taxas de criminalidade, além de poucas garantias e mecanismos de proteção básica aos cidadãos. Esse contexto de instabilidade favoreceria a emergência de práticas mais violentas e repressivas tanto por parte da sociedade civil, quanto por parte das forças policiais.

Os autores identificam processos similares de intensificação das medidas punitivas e de restrição das liberdades civis na América Latina com as "democracias mais consolidadas" como os EUA e países do Reino Unido, especialmente após os ataques de 11/09 nos EUA e os de 7/7 na Inglaterra. Os autores destacam que o contexto de forte instabilidade e medo instaurados em muitos destes países se apresentam como obstáculo às instituições democráticas à medida que fomentam políticas de segurança mais discriminatórias, reforçando divisões étnicas e religiosas. Karstedt e LaFree (2006) apenas identificam a intensificação das medidas repressivas a partir do 11/09, sem mencionar de forma detida e exemplificada alguma experiência de país latino-americano que efetuou mudanças na orientação geral das políticas de segurança. 0 principal argumento dos autores, portanto, é que a política do medo e a produção da insegurança acirram ainda mais as medidas repressivas, tanto em "regimes autoritários" como nas "democracias maduras".

Para fechar este primeiro grupo de artigos, citamos o importante trabalho de Whitaker sobre os efeitos da "guerra ao terror" nas legislações. Whitaker (2007) faz a análise das implicações da disseminação e implementação de projetos de lei antiterrorismo pós-11/09 em países da África, Ásia e América Latina, bem como as dinâmicas políticas internas que acompanharam tais processos.

A autora observa as tentativas de manutenção do equilíbrio entre a garantia dos direitos civis e a promoção das políticas de segurança nos países "em desenvolvimento" com foco no processo de aprovação e implementação desses projetos de lei entre setembro de 2001 e março de 2007. 0 objeto empírico da autora são 33 países que introduziram uma legislação específica antiterrorismo em seus parlamentos. Como fonte, ela analisa os relatórios apresentados ao Comitê Contra o Terrorismo da ONU (CTC) nos quais pelo menos 33 países da África, Ásia e América Latina introduziram uma legislação antiterrorismo específica nos seus parlamentos. 
A preocupação da autora diz respeito aos possíveis impactos da introdução de dispositivos antiterrorismo em realidades políticas variadas que englobam desde países com "instituições democráticas bem consolidadas" até aqueles em "recente processo de transição e abertura política". Para Whitaker (2007), as principais preocupações sobre os dispositivos estabelecidos pela legislação antiterrorismo são: i) abrangência da definição de terrorismo; ii) supressão de um conjunto de procedimentos legais para realizar prisões; iii) autorização para monitorar e trocar informações sobre os cidadãos entre órgãos de segurança nacionais e internacionais; iv) imposição de restrições a liberdade de expressão. Os dados da pesquisa apontam que dos 33 países que apresentaram projetos de lei antiterrorismo no período pesquisado, 14 países aprovaram projetos em menos de um ano de debate. Outros 13 países precisaram de no mínimo um ano para aprová-los e seis deles, embora tenham apresentado o projeto de lei, ainda estavam em processo de debate sobre a implementação. Ao comparar esses diferentes grupos com o ranking disponibilizado pela Freedom House (WHITAKER, 2007, p. 1020), que versa sobre a abertura democrática de cada país, a autora constata que os países que mantiveram mais tempo de debate para aprovação do projeto de lei, em geral, também haviam sido classificados como pela Freedom House como "mais democráticos" e que o grupo de países que haviam aprovado os projetos mais rapidamente estavam classificados como os países "mais autoritários". No que diz respeito à América Latina, a autora incluiu Cuba (menos de um ano para aprovação), El Salvador e Colômbia (mínimo de um ano para a aprovação).

Como consideração final, Whitaker (2007, p. 1020) destaca a rápida difusão da política de segurança antiterrorismo, promovida por diversas instituições e órgãos internacionais, frequentemente associada a uma tentativa de controle e intervenção estadunidense, que tem se materializado na forma de medidas que restringem os direitos civis em favor do discurso da segurança nacional. Por outro lado, a autora enfatiza que a promoção de tais dispositivos vem culminando na disseminação do debate sobre os limites do poder desses órgãos sobre grupos minoritários e sobre a sociedade civil. Nesse sentido, a promoção da legislação antiterrorismo mesmo em países com democracias "ainda recentes" foi um mecanismo de favorecimento do debate e do engajamento da sociedade civil organizada. Portanto, para Whitaker (2007), o governo estadunidense parece em alguns momentos alcançar de forma "contraditória" seu objetivo de "promover a democracia" por meio da expansão dessas políticas de combate ao terrorismo 0 que, por outro lado, coloca em boa parte dessas movimentações uma forte reação e resistência aos EUA. 
Neste item, agrupamos um conjunto de pesquisas sob o rótulo de enfoque hegemônico. Embora os artigos possuam abordagens razoavelmente diversas é possível identificar como traço comum a crença na intensificação da política estadunidense de segurança para a região. De outra forma, os textos diagnosticam (com pouca pesquisa empírica) uma política de segurança pública do tipo "tolerância zero", vigente nos anos 90 nos EUA, e exportado para a América Latina. Após os acontecimentos de 11/09 este processo se intensifica gerando uma "convergência de pólos" (expressão utilizada por Godoy, 2005), que sintetiza a importação pela América Latina do modelo europeu e americano de políticas (sociais e econômicas), bem como, no que diz respeito às reformas das instituições de justiça criminal.

0 termo que melhor traduz este modelo difundido na América Latina é a chamada Mano Dura. Tal modelo de política é marcada por privilegiar a segurança do Estado em detrimento da proteção das garantias e direitos civis e ainda, é fortemente calcada na repressão de um "inimigo interno" construído (frequentemente) sob a promoção ou proteção americana. Tais modelos "mão de ferro" se difundiram, em maior ou menor medida, por países da região como Honduras, El Salvador, Colômbia sob o signo da chamada "prevenção".

\section{O ENFOQUE PERIFÉRICO}

Contrapondo esta literatura majoritária exposta acima, um menor número de autores, como Langer (2007) propõe o argumento inverso: a "difusão da periferia". Ou seja, examinando como regras, normas e políticas se disseminam também dos "países periféricos" aos "países centrais" ou para outros países "periféricos". Neste sentido, a onda de reformas e mudanças nos Códigos Penais (e na segurança pública) na América Latina não é apenas um contra-exemplo para os modelos existentes predominantes (centro x periferia), mas constituiria a base para um novo modelo teórico reivindicado por este autor no debate acadêmico.

Assim, Langer (2007) analisa as reformas nos códigos de procedimento criminal na América Latina nos últimos 15 anos amparado na análise documental e entrevistas com 62 participantes dessas reformas. 0 autor alega que houve uma onda latino-americana de reformas (entre 1991 e 2006, 14 dos 19 países da região haviam aderido às reformas) que apresenta um conjunto de características distintivas que desafiam categorias e modelos analíticos vigentes. Segundo Langer, o "ineditismo" da experiência latino-americana - contrariando diversas correntes teóricas e quadros analíticos existentes - não está vinculado a quaisquer 
movimentos sociais mais amplos, redes governamentais transnacionais ou comunidades acadêmicas, mas se tratou basicamente de uma rede "independente" de advogados latino-americanos que se engajaram tanto na elaboração quanto na implementação dos novos códigos criminais na região. Langer nomeia esse grupo de agentes como rede de ativismo especializada (activist expert network) do sul.

0 autor argumenta que um fator chave de êxito dessa "rede de ativismo especialista do sul" foi sua habilidade de convencimento com "influentes atores internacionais" como a United States Agency for International Development (USAID), bem como bancos, agências internacionais e lideranças políticas da América Latina. Para Langer (2006), a rede de atores ainda foi capaz de lançar mão da crescente adesão a essas reformas como mecanismo de pressão política sobre outros países da região, disseminado a ideia de uma tendência regional em direção a esse processo. Esses atores locais teriam desencadeado esse processo massivo de reformas na América Latina "exclusivamente motivados" pelas inadequações identificadas nos códigos de procedimento criminal, enfrentando diversos obstáculos relacionados à "falta" de regulamentação e transparência nos procedimentos das instituições de justiça. Apesar das particularidades e características distintivas dos processos de reforma, o autor enfatiza um aspecto central em todos esses processos: todos os países tratam de uma transição do sistema criminal inquisitorial para o acusatório.

Segundo o autor, os países latino-americanos invariavelmente adotadaram códigos de procedimento criminal orientados pelo modelo inquisitorial. Basicamente, esse modelo estaria estruturado em duas fases, sendo a primeira de investigação e a segunda do veredito. Ambas as fases estavam concentradas na figura do juiz, que estava encarregado tanto das investigações preliminares quanto da aplicação da sentença. Essa estruturação impunha uma série de restrições sobre os acusados que não tinham acesso total às informações sobre o processo de investigação de seu caso, que eram interrogados antes de qualquer avaliação preliminar do juiz sobre as acusações, além da obrigatoriedade da detenção preventiva a todos os suspeitos. Já a modificação para o modelo acusatorial teria trazido um conjunto de modificações aos procedimentos criminais, fazendo com que os processos deixassem de ser exclusivamente escritos e restritos, para serem também apresentados oral e publicamente, criando mecanismos de regulamentação da prisão preventiva e para que a vítima pudesse ter maior participação no processo separando as fases de investigação e de sentenciamento e retirando-as do controle exclusivo do juiz. 
Langer (2006) refuta a perspectiva hegemônica que sustenta que a onda de reformas nos códigos de procedimento criminal seria fruto de uma emulação de modelos importados de países como os EUA e outros países da Europa. Ele mesmo argumenta que embora tais redes ativistas tenham se inspirado em diversos modelos, incluindo de países do hemisfério norte, o modelo proposto pela rede latino-americana não se tratava de uma transposição ou importação de um modelo pronto para região, mas sim um processo cuidadoso de análise e adaptação desses códigos às necessidades e particularidades locais. Um dos exemplos dessa distinção, entre os modelos europeus ou estadunidenses e o modelo latinoamericano, citado pelo autor, seria a forte presença dos mecanismos alternativos de resolução de conflitos. Por fim, a perspectiva da imposição externa sustenta que essa onda de reformas seria somente reflexo da influência de países centrais sobre os países periféricos, na qual USAID e outras instituições internacionais teriam sido os atores chave de tais processos.

Entretanto, Langer (2007) destaca que a rede de ativistas especializada do sul já estava articulando tais processos de reforma em diversas instituições na região, antes da intervenção de tais agências internacionais. Dentro desse contexto, a intervenção de agências como a USAID na promoção das reformas na América Latina, antes de se caracterizar como uma determinação externa seria mais bem interpretada como um subtipo de difusão da periferia que o autor denomina como difusão triangular da periferia ${ }^{6}$. Dentro do quadro de categorias analíticas do autor, existiria o modelo de difusão horizontal ou semi-horizontal e o modelo triangular da periferia. Nos primeiros, as reformas se dariam sem a interferência de países centrais, enquanto no último essas reformas permanecem sendo idealizadas e promovidas por países periféricos, mas contando com aliados e investimentos financeiros de países centrais. Langer considera que o conjunto de reformas nos códigos de procedimento criminal empreendido nas últimas duas

\footnotetext{
${ }^{6}$ Segundo Langer (2007, p. 664) Colômbia, Honduras e Paraguai possuem elementos presentes de difusão a partir do centro, na medida em que atores dos países centrais participaram da elaboração dos códigos. Ainda assim, essas reformas apresentam mais elementos de 'difusão triangular a partir da periferia', uma vez que o papel de atores dos países periféricos foi mais importante na elaboração de código do que o de atores dos países centrais. No caso da 'difusão triangular a partir da periferia', os atores nos países periféricos são os autores intelectuais e desempenham um papel crucial na difusão de regras, normas e políticas com outros países periféricos, mas os atores dos países centrais também desempenham um papel crucial na processo de difusão. No caso de 'difusão horizontal ou semi-horizontal da periferia' as regras, normas, políticas difundem-se dos atores nos países periféricos ou semi-periféricos para outros países periféricos ou semi-periféricos, sem qualquer participação substancial dos agentes dos países centrais. Ver os modelos do autor nas páginas 623- 626.
} 
décadas na América Latina foi fruto de articulações independentes de uma rede de ativistas especialistas, oriundos de países periféricos que "habilidosamente" teriam convencido agências e atores internacionais a promover seu modelo na região. Ainda que a hipótese de Langer possa ser interessante porque considera o contexto cultural e institucional dos países latino-americanos, cabe a reflexão sobre a origem das instituições internacionais.

Nesta linha argumentativa, Mark Ungar (2008) também se detém nas reformas e mudanças nas políticas de segurança pública na América Latina após 11/09. Segundo o autor, em Honduras, por exemplo, o governo do Partido Nacional do presidente Ricardo Maduro (2003-2007) teve como foco de política de segurança as gangues de jovens (maras). Os maras, apesar da propaganda midiática de "criminosos", seriam reconhecidos (inclusive pela polícia hondurenha) como autores de menos de um terço de todos os crimes, embora suas atividades dominem a legislação criminal e os meios de comunicação.

A peça central dessa mudança legal foi a alteração do artigo penal processo de código 332 com o fim de punir com pena de prisão membros de gangues de 9 a 12 anos. Outro exemplo citado é a Law of Police and Social Co-Existence permitindo que oficiais "controlassem" as pessoas em determinadas áreas a fim de combater o crime e arbitrariamente contra os denominados "vagabundos" ou seja, sob a égide Mano Dura, as pessoas que não tem meios "honestos" de ganhar a vida ou são suspeitos ou se tornam propensos a se envolver em atividades criminosas e devem ser punidas duramente. Para Ungar (2008), esta abordagem de controle do crime e do criminoso em Honduras é baseada na ideia de que as autoridades legitimam publicamente a "escolha difícil" entre o combate à criminalidade que combine com a proteção dos direitos. Segundo a declaração do ministro Maduro de Segurança de Honduras, o novo código penal incorporava a abordagem garantista da proteção dos direitos e assim deve ser descartado por ser ineficaz contra membros de gangues crime. Juntamente com a falta de formação para implementar o código de processo penal, tem aumentado o uso de ataques em massa, prisão preventiva prolongada, confissões forçadas e assassinatos extra-judiciais de suspeitos mareros. A maioria dos agentes estatais concordaria com a estimativa de aproximadamente 2.300 execuções extrajudiciais de jovens e crianças de 1998 a 2005, sendo que quase 40\% dos quais teriam evidência de envolvimento da polícia.

Ungar (2008) cita as reformas policiais na Bolívia. A última reforma da segurança (já extinta), o Institucional Strategic Plan (2003-2007) teria sido um "rosário de ideias excelentes", mas com falta de apoio institucional. 0 plano 
incluía medidas para controlar a corrupção com o novo regulamento disciplinar; melhores serviços de habitação, educação e saúde para a polícia; incentivos econômicos para o trabalho policial e a criação de uma polícia do Tesouro para controlar as finanças da polícia. Segundo Ungar, o apoio dos EUA teria levado a melhorias nas duas primeiras áreas, mas o resto do plano caiu no esquecimento devido ao fraco apoio financeiro, institucional e político local.

Entretanto, para Ungar houve algumas "reformas encorajadouras". A maioria das acusações contra a polícia são encaminhados para o Escritório de Responsabilidade Profissional (DNRP), que investiga e envia suas provas para o Tribunal Superior de Disciplina (TDS) responsável por julgar e disciplinar o acusado. Neste período, o governo boliviano, estimulado pelos EUA, modificou o Código disciplinar da Polícia sob o signo da 'eficiência' policial e de estabelecer mais direitos aos acusados. A academia de Polícia também foi reformulada reduzindo a preparação física de 50\% a 10\% do tempo. Incentivados pelo governo a Fiscalía foi capaz de julgar casos de alto nível na Bolívia, incluindo a primeira condenação de policiais generais em 2004. Assim, o texto de Ungar localiza nesses dois países alguns pontos de inflexões na política de segurança pública, algumas vezes sob influência direta ou indireta da política norte-americana.

0 último exemplo estudado por Ungar (2008) é o caso argentino. Para Ungar, o contexto de redemocratização política junto com a crise econômica no final dos anos 1980 encadeou a reforma da polícia argentina. 0 governo do presidente Carlos Menem (1989-1999) construiu um aparato de segurança e estimulou os policiais a prevenir o crime num estágio denominado "pré-criminal". Com 0 aumento da criminalidade a níveis recordes nos anos 1990 (junto com 0 desemprego, desigualdade e pobreza), a justiça criminal teria permanecido lenta e setores da opinião pública clamavam uma adesão a uma política tipo mano dura. No contexto mais circunscrito deste texto, Ungar cita que a maioria das províncias foram relutantes ou incapazes de propor reformas policiais profundas, contexto que gerou uma pressão em matérias de políticas de segurança para 0 governo nacional do presidente Néstor Kirchner, eleito em 2003.

Durante seu primeiro ano de mandato, o presidente expulsou 107 funcionários do topo da Polícia Federal Argentina (PFA). Em seguida, em abril de 2004, introduziu um Plano de Segurança Nacional com mudanças na polícia e tribunais, como a Agência Federal de Investigações substituindo muitos chefes de polícia por policias civis eleitos ou cidadãos para avaliar promoções da polícia; tribunais do júri para muitos casos de corrupção; novas cortes para a criminalidade juvenil; deslocalização de alguns juízes e promotores para os bairros; bolsas 
de estudo para os jovens em "áreas críticas", etc. Este período, portanto, Ungar caracteriza como mais viável e amplo da era democrática na Argentina para a segurança pública, propondo uma alternativa de longo prazo à política repressiva antes em vigor no governo Menem mais aliada ao ideal mano dura.

Entretanto, o autor lista uma série de obstáculos políticos, legais e institucionais que surgiram contrários a esse plano de segurança, pois a esfera política se defronta com um público impaciente e mais inclinado a apoiar propostas "duras" e imediatas. Em 2004, o sequestro e assassinato em Buenos Aires do jovem chamado Axel Blumberg, 23 anos, levou 200 mil pessoas em frente ao Congresso Nacional. Segundo Ungar, o congresso argentino respondeu com uma série de leis elaboradas às pressas que incluíram dentre outras medidas: a redução da idade de responsabilidade criminal e sentenças mais duras para assassinos, sequestradores e estupradores forçando o governo a demissão do chefe de polícia PFA e a demissão do ministro da Justiça, Segurança e Direitos Humanos.

0 argumento final de Ungar, permeando os três exemplos rapidamente citados, chama a atenção para as mudanças na 'gestão' da segurança pública e iniciativas de reformas de quase todos os governos na América Latina, bem como a tensão entre iniciativas que visam garantir direitos civis e políticas reativa e persecutórias aliadas ao mano dura. Tais reformas, ora sob promoção americana, têm experimentado impedimentos políticos, legais e institucionais locais conforme descrito acima rapidamente, já que pressões internacionais para combater o crime, do tipo tolerância zero e da guerra ao terror, dentro dos próprios países solapam esforços para policiamento e políticas na direção do accountability ou police more accountable (UNGAR, 2008, p. 22). Para Ungar, esse contexto da política de tolerância zero, ou seu equivalente latino-americano denominado mano dura têm minado constantemente a garantia do due process of law e a legitimação pública dos direitos civis.

Este segundo bloco de textos (LANGER, 2007; UNGAR, 2008) debate a hipótese inversa: pensam a produção de modelos de políticas de segurança e reformas da justiça criminal como consequência do contexto histórico-político dos países latino-americanos, embora exista a influência (mais ou menos decisiva) dos EUA. Os textos apresentam uma maior quantidade de pesquisa empírica sobre as reformas, leis e políticas nos países latino-americanos. Denominei tal abordagem como periférica porque tais textos apareceram: i) em menor número nas bases de pesquisa de referências bibliográficas; ii) refutam (em maior ou menor grau) as modificações na segurança pública em países da América Latina 'vindas de cimá, ou seja, como reflexo de movimentos políticos e econômicos mais amplos 
exportados pelos EUA. Os autores, portanto, chamam a atenção para o caráter específico das políticas públicas de justiça criminal per se na região.

\section{CoNSIDERAÇÕES FINAIS}

Este artigo analisou parte da bibliografia acadêmica anglo-saxã que trata das tensões entre crime, democracia e justiça na América Latina no contexto posterior à chamada "guerra ao terror". Os artigos analisados apontam para a existência de dois tipos de trabalhos: i) uma produção acadêmica majoritária que aponta as inflexões determinantes sob influência dos EUA na política de segurança da América Latina após os ataques de 11/09; ii) em menor número, os trabalhos que analisam as especificidades culturais, históricas e institucionais das políticas públicas aprovadas nos países latino-americanos, muito embora se possa admitir a influência americana e de organismos internacionais em maior ou menor intensidade.

A primeira abordagem foi denominada hegemônica porque os textos nela reunidos assumiram, por perspectivas diferentes, a dominância ideológica americana no campo da produção de modelos de políticas e práticas de segurança. Esta dominância seria exercida pelos autores tanto no sentido material, bem como no conjunto de ideias e crenças presentes na representação americanizada do que é "segurança" e de quem é o "inimigo".

A segunda coletânea de textos foi denominada como "periférica". Isto porque ainda é restrita a produção de pesquisas, sustentada por pesquisa empírica (seja do ponto de vista legal, bem como do não-legal), sobre as leis, normas, políticas e práticas de segurança vigentes em um país (ou países) da América Latina, segundo suas continuidades e descontinuidades com a influência americana. Se as pesquisas aqui reunidas possuem o mérito de realizar a pesquisa empírica, por outro lado a radicalização deste pressuposto parece negligenciar as possíveis influências e relações bilaterais dos países latino-americanos com os modelos americanos de políticas de segurança, em vigor nas duas últimas décadas, que certamente repercutiram por aqui: nos anos de 1990 a chamada "tolerância zero"; nos anos 2000 a "guerra ao terror".

Ainda assim, apesar das distinções entre os dois enfoques é possível reunir um conjunto de argumentos que unem os dois pólos de textos aqui examinados:

i) Os autores que citam a "guerra ao terror" descrevem-na como uma intensificação da Guerra Fria ou pelo menos destacam a influência e 
hegemonia do paradigma americano (ou nortista) sobre as políticas de segurança e as relações bilaterais estabelecidas pelos EUA com os países latino-americanos.

ii) Os textos analisados (os "pró e contra" EUA) consideram esse posicionamento mais intervencionista após 11-09 (e menos aberto) como "ultrapassado" e contraprodutivo. Por conseguinte, diagnosticam a emergência de uma resistência aos EUA e um antiamericanismo na região presente, para estes autores, na aproximação dos países latinoamericanos com a China, Venezuela, etc.

iii) Os autores enfatizam que o "medo" e a "insegurança" (ora analisados como reais, ora produzidos socialmente) geram uma polarização da sociedade entre um "nós" e "outros" na qual a ênfase em uma política de segurança cada vez mais repressiva como o Mano Dura ocorre em detrimento da efetivação ou legitimação dos direitos civis e humanos.

iv) Os textos analisados sempre enfatizam o período de "transição democrática" como variável relevante para compreensão da "segurança" na região. Além disso, destacam as implicações da adoção de políticas como as de "contra- insurgência", "guerras às drogas" ou de "combate ao terrorismo" para o discurso de consolidação da democracia na região.

v) Por último, destacam uma suposta "fragilidade das instituições" (as nossas) erigidas após duas décadas de processo de "consolidação democrática" (neoliberal para muitos) que se daria sem melhorias substanciais nas condições de vida da população. 0 que intensifica uma resistência da sociedade civil e de outros grupos políticos de oposição contra promessas "democráticas" e desenvolvimento neoliberais.

Portanto, delineia-se a necessidade de pesquisar de forma sistemática considerando cada país latino-americano - as possíveis relações entre os modelos e medidas de segurança patrocinados pelos Estados Unidos nas instituições multilaterais e nas relações bilaterais em domínios especializados e, as tendências das políticas de segurança dos países latino-americanos na última década.

\section{REFERÊNCIAS}

AVILÉS, William. Paramilitarism and Colombia's low-intensity democracy. Journal of Latin American Studies, Cambridge, v. 38, n. 2, p. 379-408, 2006. 
CALDEIRA, Teresa; HOLSTON, James. Democracy and violence in Brazil. Comparative Studies in Society and History, Cambridge, v. 41, n. 4, p. 691-729, 1999 .

GODOY, Angelina. Converging on the poles: contemporary punishment and democracy in hemispheric perspective. Law \& Social Inquiry, Chicago, v. 30, n. 3, p. 515-548, 2005.

HERZ, Mônica. Política de segurança dos EUA para a América Latina após o final da Guerra Fria. Estudos Avançados, São Paulo, v. 16, n. 46, p. 85-104, 2002.

HUME, Mo. Mano Dura: El Salvador responds to gangs. Development in Practice, San Salvador, v. 17, n. 6, p. 739-751, Nov. 2007.

KARSTEDT, Susanne; LAFREE, Gary. Democracy, crime, and justice. Annals of the American Academy of Political and Social Science, Philadelphia, v. 605, p. 6-23, May, 2006.

LANGER, Maximo. Revolution in Latin American criminal procedure: diffusion of legal ideas from the periphery. American Journal of Comparative Law, Baltimore, v. 55, n. 4, p. 617-676, 2007.

MANN, Michael. The Crisis of the Latin American Nation-State. In: CONFERENCE THE POLITICAL CRISIS AND INTERNAL CONFLICT IN COLOMBIA, 2002. Bogotá. Paper presented...Bogotá: University of the Andes, 2002. p. 10-13.

MATTEI, Ugo. A theory of imperial law: a study on us. Hegemony and the Latin resistance. Indiana Journal of Global Legal Studies, Bloomington, v. 10, n. 1, p. 383-448, 2003.

UNGAR, Mark. Prisons and politics in contemporary Latin America. Human Rights Quarterly, Cincinatti, v. 25, n. 4, nov. 2003.

. Latin America's police: advancing citizen security? Princeton University Workshop: Violence and citizen in post-authoritarian Latin America, Mar. 7, 2008. Disponível em: <http://www.princeton.edu/piirs/projects/ Democracy\&Development/papers/Panel\%20III\%20Ungar.pdf. > . Acesso em: 7 jun. 2010.

WHITAKER, Beth. Exporting the patriot act? Democracy and the 'war on terror' in the third world. Third World Quarterly, London, v. 28, n. 5, p. 1017-1032, 2007.

ZULUAGA, Jamie; STOLLER, Richard. U. S. security policies and United StatesColombia relations. Latin American Perspectives, Newbury Park, v. 34, n. 1, p. 112-119, Jan. 2007. 